\title{
Patterning and Morphogenesis From Cells to Organisms: Progress, Common Principles and New Challenges
}

\author{
Andrew B. Goryachev ${ }^{1 *}$ and Moisés Mallo ${ }^{2 *}$ \\ ${ }^{1}$ SynthSys, Centre for Synthetic and Systems Biology, University of Edinburgh, Edinburgh, United Kingdom, ${ }^{2}$ Gulbenkian \\ Institute of Science (IGC), Oeiras, Portugal
}

Keywords: cell polarity, tissue polarity, morphogenesis, patterning, mechanical forces, phase separation

\section{OPEN ACCESS}

Edited and reviewed by:

Amanda Gay Fisher,

Medical Research Council,

United Kingdom

${ }^{*}$ Correspondence:

Moisés Mallo

mallo@igc.gulbenkian.pt

Andrew B. Goryachev

Andrew.Goryachev@ed.ac.uk

Specialty section:

This article was submitted to

Morphogenesis and Patterning,

a section of the journal

Frontiers in Cell and Developmental

Biology

Received: 03 September 2020

Accepted: 01 October 2020

Published: 06 November 2020

Citation:

Goryachev AB and Mallo M (2020) Patterning and Morphogenesis From Cells to Organisms: Progress, Common Principles and New

Challenges.

Front. Cell Dev. Biol. 8:602483.

doi: 10.3389/fcell.2020.602483
The ability to progress from simple to more complex, organized, and spatially differentiated forms, or morphogenesis, is, perhaps, one of the most fundamental properties of biological systems from individual cells to large multicellular organisms, to whole populations. Customarily, cell biology is concerned with the morphogenesis of individual cells, while developmental biology studies morphogenesis on the scales of tissues and whole organisms. We envision that the Section "Patterning and Morphogenesis" will take on the challenge of unifying these efforts focusing on their integration based on the common organizing principles. Historically, patterning and morphogenesis has been a fundamentally multidisciplinary area of research that experienced influences of many scientific disciplines outside of biology, i.e., physics, chemistry, and mathematics. Therefore, one of our goals will be to foster this spirit of multidisciplinarity and encourage contributions from classical experimental research as well as from more quantitative and theoretical fields. Even when the development of tools allowing appropriate experimental approaches to complex cellular and molecular activity was still in its infancy, theoretical models were already proposed to account for the formation of complex and highly specific morphological features. Many influential ideas generated by the twentieth century giants, such as Alan Turing, Conrad Waddington, and Lewis Wolpert, have become even more exciting now, when we can actually observe and experimentally perturb their manifestations in living biological systems.

\section{SEEING IS BELIEVING}

Currently we experience an unprecedent boom in several areas of technology that have dramatically increased the depth and detail with which the mechanisms of patterning and morphogenetic processes are explored. Most often these technological developments happened independently from each other, but their clever and creative combination has potentiated their individual power, as well as expanded their applicability. Advances in optical microscopy are among the technological developments with the highest impact in the depth, resolution and precision that can be applied to the analysis of a wide variety of cell and molecular behaviors guiding morphogenetic processes in many different in vivo and in vitro systems. Full exploitation of the power of advanced microscopic technology resulted from its association with other technological areas. For instance, concomitant development of methods to introduce different types of fluorescent labels (Shcherbakova et al., 2014) into cell structural components, many of them compatible with live imaging analyses in cells or even whole organisms, has enabled observation of morphogenetic processes at unprecedented space and time resolution. The use of advanced computational techniques has also significantly increased image analysis power. The recent success of the super resolution microscopy (Sengupta et al., 2012; Betzig, 2015) and the generation of precise active 3D models (Long et al., 2012) are just 
two examples illustrating the benefits of merging imaging and computation. These improvements allowed live observation of highly dynamic processes, such as establishment of cellular polarity, complex oscillations, and propagation of waves inside cells and tissues (Bement et al., 2015; Tsiairis and Aulehla, 2016; Wu et al., 2018; Landin Malt et al., 2019). This also allowed us to follow cell routes and fates in highly complex structures like a developing mouse embryo (Mcdole et al., 2018). Surely, these are only the appetizers for what we will witness in the coming years.

Efficient single cell technologies have also been introduced in the analysis of a variety of complex morphogenetic processes (Wagner et al., 2018; Cao et al., 2019; Delile et al., 2019; PijuanSala et al., 2019). It is expected that the power of this analytic approach will be considerably increased with the combination of protocols allowing spatial allocation of the individual cells within the tissue of origin, as well as by the assistance of systems biology methodology to infer and model gene networks regulating those processes, also leading to the generation of experimentally testable hypotheses (Tam and Ho, 2020). In addition to analytical approaches, in recent years new technologies have also expanded the toolbox permitting introduction of precisely controlled modifications in the experimental system required to evaluate the role of specific features in the generation of complex structures. The appearance of the CRISPR/Cas9-based genomic editing techniques (Adli, 2018) is among the most relevant of those new approaches, with an immediate deep impact in the field of cell and developmental biology. For instance, it has democratized the use of genetics to the analysis of patterning and morphogenetic processes. Until very recently controlled experimental alterations of gene activity were possible in only a handful of model systems, and even in them the options to modify gene expression were often limited, mostly relying on the introduction of different types of exogenous elements in the genome or interfering with gene expression machinery. CRISPR/Cas9 technology provided for the first time the possibility of introducing reverse genetic approaches to the study of cellular and developmental processes in organisms previously considered unsuited to controlled genetic modification (Martin et al., 2016; Mazo-Vargas et al., 2017; Rasys et al., 2019).

Another group of technological advances relates to the introduction of new in vitro model systems closely simulating in vivo conditions that for a variety of reasons cannot be effectively approached in their natural environment. To name but a few, in vitro reconstitutions of the MinCDE cell patterning system (Loose et al., 2008; Glock et al., 2019), mixtures of cytoskeletal polymers and their cognate molecular motors (Koenderink et al., 2009; Opathalage et al., 2019), and whole mimetic actomyosin cortices (Carvalho et al., 2013; Foster et al., 2019), dramatically accelerated our understanding of the morphogenesis in the corresponding in vivo systems. Some of these in vitro approaches had been around already for a number of years. Indeed, embryoid bodies, Keller sandwiches and a variety of tissue explants represent three classical examples of such systems that have been effectively used for decades (Doetschman et al., 1985; Keller and Danilchik, 1988; Freshney, 2016). However, the technologies for the generation of complex in vitro models evolved considerably from these early systems and are now mostly represented by structures globally known as organoids (Kretzschmar and Clevers, 2016), when they aim at mimicking specific organ structures like the brain or the intestine, and gastruloids (Beccari et al., 2018), when they intend to reproduce early stages in embryonic development.

\section{QUO VADIS?}

Given these fascinating technological advances, what are the main challenges that the broad field of patterning and morphogenesis is currently facing? Owing to the impact of the concept of morphogens introduced by Turing (1952), chemical regulation of morphogenesis has been in the spotlight for decades. Indeed, the concept of morphogens further developed by Wolpert and colleagues turned out to be exceptionally fruitful (Smith et al., 2008; Green and Sharpe, 2015; Wolpert, 2016). Supported by the discussed above modern technologies, we are presently confident that many proteins, e.g., TGF $\beta$, bone morphogenetic proteins, sonic hedgehog and WNTs, fully qualify for the role of extracellular morphogens. Interestingly, the concept of morphogens can be also productively extended into intracellular morphogenesis within the framework of the activator-substrate model (Hubatsch and Goehring, 2020). Perhaps, the best characterized intracellular morphogens are small GTPases that form membrane localized prepatterns for cytoskeletal structures and in the context of the establishment of cell polarity (Goryachev and Leda, 2017, 2019, 2020). The concept of mechanical regulation of morphogenesis was formed a long time ago, perhaps even before that of chemical regulation. However, due to the experimental difficulties and the paucity of theoretical approaches it remained in the shadow of the chemical regulation. This situation changed dramatically in the past decade due to the burgeoning development of experimental and theoretical biomechanics. One of the current grand challenges is to integrate chemical and mechanical mechanisms to achieve a new level in understanding of morphogenesis on both intracellular and multicellular levels (Howard et al., 2011; Goehring and Grill, 2013; Gross et al., 2017).

Arguably, the most recent development in the mechanisms of morphogenesis has been the recognition of the role played by the phenomenon of phase separation (Hyman et al., 2014; Banani et al., 2017). Phase separation is a well-developed concept in physics and chemistry but its relevance to biology in general and morphogenesis in particular has been largely unexplored. Presently evidence is abound that phase separation is the governing principle in control of formation of multiple cellular organelles not bound by a lipid membrane, such as centrosomes, nucleolus, and a large variety of cytoplasmic and nuclear granules and bodies (Woodruff et al., 2018; Alberti et al., 2019). The out of equilibrium nature of biological phase separation makes all the difference as it converts a rigid unidirectional aggregation of molecules into a highly plastic process which is finely controlled by cellular signaling. Another current grand challenge is to understand these mechanisms of regulation and to integrate them with the better understood patterning mechanisms by reaction and diffusion. While currently phase separation appears 
mainly relevant to the intracellular morphogenesis, it is not unlikely that phase separation also plays roles on the multicellular scale, e.g., in the formation of basal membranes, and even tissue and organism scales, such as in fascia and cartilage.

It is exciting to anticipate what the development of these new conceptual and technical advances will teach us about how cells work and interact to build complex functional structures. We hope that, in the years to come, the Patterning and Morphogenesis Section of the Frontiers in Cell and Developmental Biology will play an important role in disseminating this new knowledge among the scientific community and beyond.

\section{REFERENCES}

Adli, M. (2018). The CRISPR tool kit for genome editing and beyond. Nat. Commun. 9, 1911-1911. doi: 10.1038/s41467-018-04252-2

Alberti, S., Gladfelter, A., and Mittag, T. (2019). Considerations and challenges in studying liquid-liquid phase separation and biomolecular condensates. Cell 176, 419-434. doi: 10.1016/j.cell.2018.12.035

Banani, S. F., Lee, H. O., Hyman, A. A., and Rosen, M. K. (2017). Biomolecular condensates: organizers of cellular biochemistry. Nat. Rev. Mol. Cell Biol. 18, 285-298. doi: 10.1038/nrm.2017.7

Beccari, L., Moris, N., Girgin, M., Turner, D. A., Baillie-Johnson, P., Cossy, A.-C., et al. (2018). Multi-axial self-organization properties of mouse embryonic stem cells into gastruloids. Nature 562, 272-276. doi: 10.1038/s41586-018-0578-0

Bement, W. M., Leda, M., Moe, A. M., Kita, A. M., Larson, M. E., Golding, A. E., et al. (2015). Activator-inhibitor coupling between Rho signalling and actin assembly makes the cell cortex an excitable medium. Nat. Cell. Biol. 17, 1471-1483. doi: 10.1038/ncb3251

Betzig, E. (2015). Single molecules, cells, and super-resolution optics (nobel lecture). Angew. Chem. Int. Ed. Engl. 54, 8034-8053. doi: $10.1002 /$ anie.201501003

Cao, J., Spielmann, M., Qiu, X., Huang, X., Ibrahim, D. M., Hill, A. J., et al. (2019). The single-cell transcriptional landscape of mammalian organogenesis. Nature 566, 496-502. doi: 10.1038/s41586-019-0969-x

Carvalho, K., Lemière, J., Faqir, F., Manzi, J., Blanchoin, L., Plastino, J., et al. (2013). Actin polymerization or myosin contraction: two ways to build up cortical tension for symmetry breaking. Philos. Trans. R. Soc. Lond. B. Biol. Sci 368:20130005. doi: 10.1098/rstb.2013.0005

Delile, J., Rayon, T., Melchionda, M., Edwards, A., Briscoe, J., and Sagner, A. (2019). Single cell transcriptomics reveals spatial and temporal dynamics of gene expression in the developing mouse spinal cord. Development 146:dev173807. doi: 10.1242/dev.173807

Doetschman, T. C., Eistetter, H., Katz, M., Schmidt, W., and Kemler, R. (1985). The in vitro development of blastocyst-derived embryonic stem cell lines: formation of visceral yolk sac, blood islands and myocardium. J. Embryol. Exp. Morph. $87,27-45$.

Foster, P. J., Fürthauer, S., Shelley, M. J., and Needleman, D. J. (2019). From cytoskeletal assemblies to living materials. Curr. Opin. Cell. Biol. 56, 109-114. doi: 10.1016/j.ceb.2018.10.010

Freshney, R. I. (2016). Culture of Animal Cells: A Manual of Basic Technique and Specialized Applications. Hoboken, NJ: Wiley-Blackwell.

Glock, P., Brauns, F., Halatek, J., Frey, E., and Schwille, P. (2019). Design of biochemical pattern forming systems from minimal motifs. Elife 8:e48646. doi: $10.7554 /$ LLife.48646

Goehring, N. W., and Grill, S. W. (2013). Cell polarity: mechanochemical patterning. Trends Cell Biol. 23, 72-80. doi: 10.1016/j.tcb.2012.10.009

Goryachev, A. B., and Leda, M. (2017). Many roads to symmetry breaking: molecular mechanisms and theoretical models of yeast cell polarity. Mol. Biol. Cell 28, 370-380. doi: 10.1091/mbc.e16-10-0739

Goryachev, A. B., and Leda, M. (2019). Autoactivation of small GTPases by the GEF-effector positive feedback modules. F1000Res 8:F1000 Faculty Rev-1676. doi: 10.12688/f1000research.20003.1

\section{AUTHOR CONTRIBUTIONS}

All authors listed have made a substantial, direct and intellectual contribution to the work, and approved it for publication.

\section{FUNDING}

Work in Goryachev Lab was supported by the Biotechnology and Biosciences Research Council of UK grants numbers BB/P01190X and BB/P006507 and LISBOA-01-0145-FEDER030254 (FCT, Portugal).

Goryachev, A. B., and Leda, M. (2020). Compete or coexist? Why the same mechanisms of symmetry breaking can yield distinct outcomes. Cells 9:2011. doi: 10.3390/cells9092011

Green, J. B., and Sharpe, J. (2015). Positional information and reaction-diffusion: two big ideas in developmental biology combine. Development 142, 1203-1211. doi: 10.1242/dev.114991

Gross, P., Kumar, K. V., and Grill, S. W. (2017). How active mechanics and regulatory biochemistry combine to form patterns in development. Annu. Rev. Biophys. 46, 337-356. doi: 10.1146/annurev-biophys-070816-0 33602

Howard, J., Grill, S. W., and Bois, J. S. (2011). Turing's next steps: the mechanochemical basis of morphogenesis. Nat. Rev. Mol. Cell. Biol. 12, 392-398. doi: 10.1038/nrm3120

Hubatsch, L., and Goehring, N. W. (2020). Intracellular morphogens: specifying patterns at the subcellular scale. Curr. Top. Dev. Biol. 137, 247-278. doi: 10.1016/bs.ctdb.2019.11.006

Hyman, A. A., Weber, C. A., and Jülicher, F. (2014). Liquid-liquid phase separation in biology. Annu. Rev. Cell Dev. Biol. 30, 39-58. doi: 10.1146/annurev-cellbio-100913-013325

Keller, R., and Danilchik, M. (1988). Regional expression, pattern and timing of convergence and extension during gastrulation of Xenopus laevis. Development 103, 193-209.

Koenderink, G. H., Dogic, Z., Nakamura, F., Bendix, P. M., Mackintosh, F. C., Hartwig, J. H., et al. (2009). An active biopolymer network controlled by molecular motors. Proc. Natl. Acad. Sci. U.S.A. 106, 15192-15197. doi: 10.1073/pnas.0903974106

Kretzschmar, K., and Clevers, H. (2016). Review organoids: modeling development and the stem cell niche in a dish. Dev. Cell 38, 590-600. doi: 10.1016/j.devcel.2016.08.014

Landin Malt, A., Dailey, Z., Holbrook-Rasmussen, J., Zheng, Y., Hogan, A., Du, Q., et al. (2019). Par3 is essential for the establishment of planar cell polarity of inner ear hair cells. Proc. Natl. Acad. Sci. U.S.A. 116, 4999-5008. doi: $10.1073 /$ pnas. 1816333116

Long, F., Zhou, J., and Peng, H. (2012). Visualization and analysis of 3D microscopic images. PLoS Comput. Biol. 8:e1002519. doi: 10.1371/journal.pcbi.1002519

Loose, M., Fischer-Friedrich, E., Ries, J., Kruse, K., and Schwille, P. (2008). Spatial regulators for bacterial cell division self-organize into surface waves in vitro. Science 320, 789-792. doi: 10.1126/science.11 54413

Martin, A., Serano, J. M., Jarvis, E., Bruce, H. S., Wang, J., Ray, S., et al. (2016). Article CRISPR/Cas9 mutagenesis reveals versatile roles of hox genes in crustacean limb specification and article CRISPR/Cas9 mutagenesis reveals versatile roles of hox genes in crustacean limb specification and evolution. Curr. Biol. 26, 14-26. doi: 10.1016/j.cub.2015.11.021

Mazo-Vargas, A., Concha, C., Livraghi, L., Massardo, D., Wallbank, R. W. R., Zhang, L., et al. (2017). Macroevolutionary shifts of WntA function potentiate butterfly wing-pattern diversity. Proc. Natl. Acad. Sci. U.S.A. 114, 10701-10706. doi: 10.1073/pnas.1708149114

Mcdole, K., Guinard, L., Amat, F., Berger, A., Malandain, G., Roger, L. A., et al. (2018). In toto imaging and reconstruction of post- implantation 
mouse development at the single- cell level. Cell 175, 859-876. doi: 10.1016/j.cell.2018.09.031

Opathalage, A., Norton, M. M., Juniper, M. P. N., Langeslay, B., Aghvami, S. A., Fraden, S., et al. (2019). Self-organized dynamics and the transition to turbulence of confined active nematics. Proc. Natl. Acad. Sci. U.S.A. 116, 4788-4797. doi: 10.1073/pnas.1816733116

Pijuan-Sala, B., Griffiths, J. A., Guibentif, C., Hiscock, T. W., Jawaid, W., CaleroNieto, F. J., et al. (2019). A single-cell molecular map of mouse gastrulation and early organogenesis. Nature 566, 490-495. doi: 10.1038/s41586-0190933-9

Rasys, A. M., Park, S., Ball, R. E., Alcala, A. J., Lauderdale, J. D., and Menke, D. B. (2019). CRISPR-Cas 9 gene editing in lizards through microinjection of unfertilized oocytes. Cell. Rep. 28, 2288-2292. doi: 10.1016/j.celrep.2019. 07.089

Sengupta, P., Van Engelenburg, S., and Lippincott-Schwartz, J. (2012). Visualizing cell structure and function with point-localization superresolution imaging. Dev. Cell 23, 1092-1102. doi: 10.1016/j.devcel.2012.09.022

Shcherbakova, D. M., Sengupta, P., Lippincott-Schwartz, J., and Verkhusha, V. V. (2014). Photocontrollable fluorescent proteins for superresolution imaging. Annu. Rev. Biophys. 43, 303-329. doi: 10.1146/annurev-biophys-051013-022836

Smith, J. C., Hagemann, A., Saka, Y., and Williams, P. H. (2008). Understanding how morphogens work. Philos. Trans. R. Soc. Lond. B. Biol. Sci 363, 1387-1392. doi: $10.1098 /$ rstb.2007.2256

Tam, P. P. L., and Ho, J. W. K. (2020). Cellular diversity and lineage trajectory: insights from mouse single cell transcriptomes. Development 147:dev179788. doi: $10.1242 /$ dev. 179788
Tsiairis, C. D., and Aulehla, A. (2016). Self-organization of embryonic genetic oscillators into spatiotemporal wave patterns. Cell 164, 656-667. doi: 10.1016/j.cell.2016.01.028

Turing, A. M. (1952). The chemical basis of morphogenesis. Philos.Trans. R. Soc. Lond. Ser. B Biol. Sci. 237, 37-72. doi: 10.1098/rstb.1952.0012

Wagner, D. E., Weinreb, C., Collins, Z. M., Briggs, J. A., Megason, S. G., and Klein, A. M. (2018). Single-cell mapping of gene expression landscapes and lineage in the zebrafish embryo. Science 360, 981-987. doi: 10.1126/science.aar4362

Wolpert, L. (2016). Positional information and pattern formation. Curr. Top. Dev. Biol. 117, 597-608. doi: 10.1016/bs.ctdb.2015.11.008

Woodruff, J. B., Hyman, A. A., and Boke, E. (2018). Organization and function of non-dynamic biomolecular condensates. Trends Biochem. Sci. 43, 81-94. doi: 10.1016/j.tibs.2017.11.005

Wu, Z., Su, M., Tong, C., Wu, M., and Liu, J. (2018). Membrane shape-mediated wave propagation of cortical protein dynamics. Nat. Commun. 9, 136-136. doi: 10.1038/s41467-017-02469-1

Conflict of Interest: The authors declare that the research was conducted in the absence of any commercial or financial relationships that could be construed as a potential conflict of interest.

Copyright $\odot 2020$ Goryachev and Mallo. This is an open-access article distributed under the terms of the Creative Commons Attribution License (CC BY). The use, distribution or reproduction in other forums is permitted, provided the original author(s) and the copyright owner(s) are credited and that the original publication in this journal is cited, in accordance with accepted academic practice. No use, distribution or reproduction is permitted which does not comply with these terms. 